\title{
Realization of Professional-Pedagogical Communication in Ensemble Class
}

\author{
Tatyana Varlamova \\ Russian State Specialized Academy of Arts \\ Moscow, Russia \\ E-mail: varlamovat@yahoo.com
}

\begin{abstract}
The article deals with the process of professionalpedagogical communication in the ensemble's class, the interaction of the teacher and students, the exchange of information when cooperating on musical works, selfknowledge and self-expression of the individual in joint music making, the educational impact of collective instruction, and the pedagogical leadership styles.
\end{abstract}

Keywords-communication; ensemble; teacher; leader; professional; personality

\section{INTRODUCTION}

Communication is one of the most complex areas of human objective reality and the most important sphere of the process of education. Needless to say, communication can be taught only in the context of properly organized pedagogical communication. "The very communication of the educators and the trainees takes a form of an essential nature and serves as an important professional category of the pedagogical activity." [4, p. 93]

Psychologists underline that "communication is a complex, multifaceted process of getting into rapport with and cultivating contacts between people, mostly in joint activities." It comprises: information sharing, development of the concerted interaction strategy, apprehension of other individuals, comprehension of them". [3, p. 79]

Education science considers communication as "cooperation between two or more people with a view to establishing and maintaining interpersonal relations, achieving the overall result of a joint activity". [8, p. 69]

Vocational and pedagogical communication is meant as "the system of cooperation between the educator and the trainee, the subject matter of which is the information sharing, the perception of the person and to impact from the educational point of view". "The educator acts as an initiator of this process, arranges and controls it." [1, p. 354].

The nature of communication manifests itself in its basic functions, formulated by the creator of the "pedagogical communication" trend within the Russian didactics - V.A. Kan-Kalic. He highlights the following functions:

- informational and communicative, aimed at the perceptual unity of the conversation partner through feelings, memory, attention, imagination;
- the function of interpersonal relationships establishing based on manifesting genuine interest in the conversation partner and the purposeful development of communication;

- the function of people's interpersonal influence to find the factors that would help to control the behavior of the talkers;

- the function of adaptation during the communication process, which constitutes a system of methods (psychological, physical, pantomime, verbal, motor), which is appropriately employed according to the circumstances;

- the internal functions of communication which are aimed at creating the appropriate general state in the process of communication; to empower the person; to develop the skill to watch, listen; to cultivate a "gift to attract people" (charm); to create a sense of human worth; to keep a sense of proportion, et al. [cit. ex. 1, p. 355-357]

The efficiency of communication in each particular case depends on the subjective preconditions of communication to which V.A. Kan-Kalic refers: creative orientation; perception or mutual arrangement under the traditional forms of communication; the mood, i.e. the psychological tone of communication; sympathetic understanding and a wish to understand each other.

\section{THE ESSENCE OF COMMUNICATION IN ENSEMBLE CLASS}

The characteristics of the development of communication in the ensemble class are determined by the nature of the educational guidance, namely: the developed personality of students, their cultural, educational, professional demands, the preponderance of self-education and self-improvement and life experience. Owing to the development of the masterful performance on folk instruments, as well as the use of a variety of academic and folklore repertoires, the ensemble performance has developed into a separate branch of musical art.

On the one hand, the instrumental ensemble, as a group of musicians involved in the performance process, is a consequence of conscious and deliberate educator's 
influences, who defines the program and the repertoire, the organizational framework, the number of participants, the parties' assignments, and the target orientation. Alternately, the ensemble can develop independently and be subject to special socio-psychological objective laws with distinctive and specific forms of communication. The process of communication between a teacher and students in an ensemble class may be composed of mutual understanding and ability to predict each other's behavior, or of undesirable disengagement and inability to understand each other's behavior, which leads to conflicts.

Relevant knowledge and experience can be transferred to students only through communication during the joint musicmaking in the ensemble class. Reflecting the peculiarities of the student ensemble, certain periods of its formation can be distinguished: first, these are the processes of introduction and appreciation of each other; identifying the differences of the ensemble participants, i.e., forecasting communication obstacles according to the types of training or concert and performance experience; second, managing communications while selecting targets and methods of work; and third, the successful accomplishment of the communication process involves an analysis of the established contacts, demonstrated by the willingness of all ensemble performers to reach musical and artistic objectives.

Three communication aspects may be distinguished in the process of joint playing of music: communicative, interactive, and perceptional. Communicative connection, based on the mutual understanding between two and more ensemble members, consists of the sharing of information, ideas, attitudes and interests. The interactive communication aspect is to develop a common strategy for relationships. The development of teamwork consists of sharing between the ensemble members not only the goals and objectives, but musical performing styles as well. The perceptive aspect of communication, as a direct reflection of the objective reality with the organs of the senses, is aimed at the process of perception of other ensemble members, the development of their image, the identification of their psychological properties and the characteristics of their behavior, and the establishment of interaction on this basis.

Teaching practicum demonstrates that the knowledge by the head of the ensemble of their own subject and methods of teaching is not sufficient. The teacher must master the types and methods of communication as well. In fact, pedagogical communication in the "teacher-trainees" system is an aspect of professional communication which is an integral part of the duty of a teacher in higher education, teacher, organizer, educator, manager, etc. [2]

\section{StAGES OF COMMUNICATION}

Vocational and pedagogical communication realization in the process of the ensemble organization is carried out in stages. Each manager defines the theme of the lesson; clarifies the repertoire, objectives and range of issues for consideration; and chooses the necessary materials, with due regard to the manager's own experience in preparation for the lesson. In addition, the objectives and content of each lesson are determined by the teacher on the basis of the program requirements, the repertoire strategy, commitment of the ensemble members and communicative relations, and the didactic, educational and growth objectives.

The first stage of communication - predicted - is a modeling of communication under preparation for the immediate rehearsal of the ensemble, scheduling the communicative structure of the classes. The following provisions must be highlighted: first, efficiency of the arrangement of initial rehearsal process and timely transition from the organizational procedures to direct work on the piece of music; second, the elimination of emotional tension and the negotiation of stereotypic and negative attitude towards individual students; and, third, the development of a sense of teamwork and the arrangement of holistic contact with students based on propensity and friendliness. The emotional unity of the teacher and the students, the sense of productivity of the relationship and of the prospects for their development, and the creation of a truly creative mood are important conditions at the first stage.

In preparation for the rehearsal, it is also necessary to take into account the personal feelings of the students, their thoughts, circumstances, their willingness to be, according to the outstanding Soviet teacher-innovator, V.A. Sukhomlinsky an "educate". [9] It is possible to call this preparatory stage the organizational point of the social and pedagogical interactions aimed at the development of the student's identity. In psychologists A.V. Petrov's opinion, fixation of certain character traits of the individual is subordinate to the mechanisms of inclusion of the individual in these communities and integration into them. The educational process approximates to the dialogue between equal people, each of whom in some sense activates and enriches the other in interpersonal communication. [6] Communication with the teacher at this stage permits involvement of a wide range of pedagogical techniques, such as the verbal review of the musical text, logical analysis of the dramatic composition of the creation, etc.

The second stage of communication is the arrangement of communication with the ensemble members during the direct analysis of the piece of music. The form of communication with students chosen during the musical classes, in specific circumstances, also forms the foundation for the selection of material for individual communication. That is why it is important to design a communication system that would correspond to the anticipated needs. There will be a need to communicate informative characteristics of the forthcoming impact at the moment of work. This need will also depend upon the repertoire of different styles and genres, or the plan of its educational impact. In fact, the use of methods, techniques and means are determined not only by the chosen theme and the type of the classes, but by the level of special musical and technical training of the ensemble performers. Additionally, their psychological and age features, and the personal occupational and pedagogical characteristics of the head of the ensemble must be considered. These conditions determine the nature and process of communication with the students, including the establishment of contact, the expression of absolute creative 
compassion, the proficient use of recommended practices, the effectiveness of explanations, the validation of conclusions, and comments on the execution, text editing, etc.

The third stage is a long, systematic management of communication in the evolving musical and pedagogical process. This communication is associated with the maintaining and development of the tradition of musical communication, which includes the sound embodiment of a musical image. It also includes the creation of audio-motor images based on acoustical perception, and cultivation of intonation relations and creating intonation mentality. It is possible to say that this vocational and pedagogical communication has an intensive and transforming nature. During the long work on pieces of music in the ensemble class, the teacher deals with constantly evolving communications objectives, regulates the communication process, encourages the participation of students in the established system of communication, and looks for constant compliance with the methods of influence and the communication system.

The final stage of communication is an analysis of the implemented communication system and a simulation of the communication system in preparation for the concert, predicting the structure of the upcoming ensemble performance in the face of an audience. It is important that the analysis of the executed communication deals with the feeling of satisfaction or dissatisfaction after the concert presentation. This communications element involves the informative aspects of pedagogical communication, the principles of analyses, discussion and evaluation of the ensemble performance, and the choice of educational means.

\section{THE TEACHER'S PERSONALITY}

It is known that communication is realized through the persons' relationship, but the relations between art and pedagogics should be determined by the education objectives. K. Ushinsky wrote, "In education everything should be based on the identity of the tutor because educational power pours out only from the living source of the human person." No charters and programs, and no artificial body of the institution can replace the individual in education. Only a person can act for the development and the personal identification; only nature can form the "nature". [10, p. 171]

Thus, the heart of diverse creative activities of the ensemble is the personality of a teacher, and it is correctly said that "only the one who burns himself is able to inflame." The head of the ensemble ought to have a capability of matching of the partners who are psychologically suiting one another for joint communication and music-making, and to define the organizational structure and orientation, including the joint choice of the repertoire.

In addition, each teacher must have the following personal and professional qualities for ensuring the maximum effect of impact on collective of the ensemble: operational excellence; a high level of elocution and general culture; mastering of the technique of training and of holding group musical rehearsals; and the ability to interact actively with the students, including creating problem-based situations with the aim of developing cognitive independence of the participants in the joint cognitive and audio-motor activity.

The interaction efficiency of the head of the ensemble with the students is in many respects determined by observance of a pedagogical sense of delicacy. The pedagogical sense of delicacy requires not only a polite mode of address, but also an accompanying fairness, the ability to listen and explain patiently, and a sincere manner of communication with students. The teacher shall be the carrier of such important qualities as optimism and goodwill, which are not less important than an operational excellence. The pedagogical optimism and the optimistic mood of the classes are the result of the head's conviction and faith in each of the students, the willingness to work with them, and to assist in the achievement of mastery.

Within the framework of the ensemble arts, the problem of pedagogical communication is considered in connection with the pedagogical activity style, depending on the individual qualities of the teacher. Undoubtedly, effective pedagogical communication enables the maximum use of the teacher's internal and external personal qualities. It establishes creative opportunities for the individual development in the collective, and it bars the emergence of a "psychological barrier". Psychologists refer to the ability to assess a situation in a flexible manner, to take care of the trainees, to think, wisdom, positive attitude, and creative thinking as the internal qualities or inner world of the individual. Conduct and image, i.e., artistry; ability to act; neatness; fashion sense; trained, clear speech; and graceful gesticulation they consider as the external qualities of the personality.

\section{Pedagogical Management Style}

It is possible to designate several basic pedagogical styles for managing the students in the ensemble which are based on different styles. These include: autocratic, authoritative, directive, liberal, ignoring, laissez-faire, inconsistent, improvisational, regulated, general, and democratic.

In the case of autocratic style, that is, the absolute leadership style, the teacher exercises exclusive collective management, preventing students from expressing their views and remarks. At the same time, the authoritarian or imperative leadership style allows students to participate in the discussion of collective life, but the decision is made, ultimately, by the teacher in accordance with his preferences. (The directive style of communication has exactly the opposite characteristics.) A manager with such an autocratic style of communication tries to keep a distance with students. In communication he is formal and official, decisive, firm and demanding, doesn't like it when his decisions are contested, ignores the requirements of the collective, etc. Most often, such teacher is dogmatic, underestimates the executive capabilities of musicians of an ensemble.

The liberal style of communication is a consequence of indiscriminate thinking, when the teacher doesn't have their own opinion and when they lacks perseverance in the transfer of knowledge to students. A similar style of 
communication is sometimes called "non-involvement" or "indifferent". The ignoring, laissez-faire and inconsistent styles of collective management lead to the disorganization and context-based system of relations between the teacher and students, and to the emergence of conflict situations.

The improvisational and regulated styles of pedagogical impact are quite different. If a regulated style restricts the role of the participants in the pedagogical process, following well-defined certain rules, the improvisational style permits students to find solutions in the newly emerging situations and non-standard conditions, which is characteristic the creative performing process.

Favorable opportunities for vocational training in the ensemble are most often created utilizing the democratic style of communication. According to the doctrine of the ancient philosopher Socrates, this style is characterized by the recognition of the student's right to independence of judgments and the promotion of such independence; the development of educational work based on encouragement and stimulation; the desire to generate a high self-esteem and faith in their abilities; the desire to rally students into a group of adherents; and by the ability to design a person of the future on the basis of his or her own potential.

Summarizing, it is possible to characterize the best management style in an ensemble class as an improvisational or democratic style. These styles are characterized by the simplicity and sincerity in the treatment of students, respect for the dignity of each participant, the responsiveness and attention to musical and executive abilities, and communication with them as with equals. Creative search, expression of requirements in the form of a request, proposals, offers, recommendations, the disadvantages of imposing one's opinion on others also are the features of this style. In practice, for each musical band, there is a general, holistic style of communication between the teacher and the students which usually creates and defines the collective, psychological and moral atmosphere of the ensemble.

\section{CONCLUSION}

The professional and pedagogical interactions in the ensemble fulfils the function of a moderator of the pedagogical impact in general. In addition, they actualize the functions of training and education, mainly for the teacher. Many of the tasks that are instrumental to them are involved. Specifically: relationships management, optimization of interactions with students, and improvement of the efficiency of the educational process in general. All this demonstrates that the process of communication in the ensemble is a category that is rich in educational functions and creative objectives, the instrument of implementation of which is communication.

The performing experience shows the pedagogical impact in the ensemble class shall be mediated by the process of communication and its identity at certain stages of the work on musical compositions. The specifics of the creative communication depend upon the current level of training. In the development of the musical and art repertoire, spiritual communication and social and intellectual needs of members of the ensemble are implemented in the teaching. Thus, education and information developing functions of pedagogical impact are enhanced.

One of the greatest thinkers of the ancient world, Confucius wrote: "Deliver a sermon only to those who seek knowledge ... Teach only those who are capable of ... Do not try to act where there is no hope of success ..." [5, p. 551].

It should be noted that, to a large extent, the organization of the training process in the ensemble class is determined by the creation of a positive emotional background of education. This effects not only terms of attendance but also the degree of student involvement in the musical and creative process. A positive mindset as a rule, has creative character. This creative character includes a capability to comprehend and interpret the personality and professional behavior of another participant, and the ability to predict the results of forthcoming communication and cooperation.

Interest acts as a catalyst for collective education, exerting its impact on both the quality of the organization and its content. However, the lack of interest in musical and pedagogical practices leads to formalism, superficial completion, and, as a result, to pseudo-creativity. The ensemble member's indifference to classes also arises when it is unnecessary personally for him, but also for other members of the ensemble. The doctrine of interest means the awareness of the importance of teaching, its relationship to instrumental and practical activities, the participation in creative searches, cooperation and co-creation between the teacher and the students, the optimism, respect, the emotional comfort in communication.

Thus, the best pedagogical communication in the ensemble class is that communication which creates the conditions for development of interest by students. This leads to enhancement of professional mastery and general culture, provides independent creative activity, and encourages students to be guided by their own efforts. This incorporates physical requirements and the purposes, motives, and will in the learning process. It is obvious that the teacher's communication becomes a significant educational element, expressed in the strengthening of his moral base. In the words of the famous Czech teacher J. Komensky, "under the name of morality, we have in mind not only external decorum, but the entire inner basis of motives as well". [5, p. 391]

It is fair to say that the complex unity of musical and artistic mastery involves creative communication which, in turn, involves the social and psychological, educational and moral objectives of education. Creative communication imposes increased demands on the communication skills of the teacher as the head of an ensemble in higher education institutions.

\section{REFERENCES}

[1] Kazakova A.G. Pedagogics of professional education: Monograph. Moscow: Econ-Inform, 2007. 
[2] Kan-Kalik V.A. Grammar of communication. -Moscow, Rospedagenstvo, 1995.

[3] Brief psychological dictionary. - M., 1985.

[4] Leontiev A.A. Pedagogical communication. - M., 1979.

[5] The wisdom of millennia. Encyclopedia / Comp.N.Berezin; Under the general ed. A.Yanak. - M.: OLMA-PRESS, 2006.

[6] General Psychology: Textbook. For stud. Ped. In-tov / under. Ed. AV Petrovskogo.-3rd ed., Pererab. And additional. - Moscow: Education, 1986.

[7] Panfilova A.P. Business communication in professional activities. - St. Petersburg, 2001

[8] Russian Pedagogical Encyclopedia: In 2 vols / Ch. Ed. V.V. Davydov. - Moscow: The Great Russian Encyclopedia, 1998.

[9] Suhomlinsky V.A. About education. - Moscow: Political Literature, 1982.

[10] Ushinsky K.D. Coll. Op. - T. 23. - M., 1978. 